\title{
As percepções sociais frente à implantação de uma Instituição de Longa Permanência para Idosos em um município do Vale do Taquari/RS, Brasil
}

Social perceptions compared to the implementation of a Long Term Care Institutions for Elders in a city of Vale do Taquari / RS, Brazil

\author{
A. D. Zagonel; A. E. K. Costa; L. F. Pissaia*; C. Moreschi \\ Centro de Ciências Biológicas e da Saúde, Centro Universitário Univates, 95900-000, Lajeado-RS, Brasil \\ *lpissaia@universo.univates.br
}

(Recebido em 24 de setembro de 2016; aceito em 12 de dezembro de 2016)

\begin{abstract}
O principal objetivo deste estudo foi avaliar as percepções sociais diante da implantação de uma Instituição de Longa Permanência para Idosos em um município do Vale do Taquari/RS, Brasil. Caracteriza-se como um estudo descritivo e exploratório com abordagem qualitativa. A coleta de dados foi realizada por meio de entrevistas individuais com três pessoas residentes no bairro ao qual a Instituição de Longa Permanência para Idosos está em processo de implantação. Os resultados demonstraram que a implantação de uma instituição para idosos exige uma conscientização social quanto à sua necessidade local. Verificou-se que a qualificação da assistência prestada ao idoso oferece subsidios para as familias aderirem a esse outro modelo de cuidados. A apresentação da estrutura para a sociedade e realização de atividades multidisciplinares apresentam-se como principios qualificadores para sua aceitação enquanto espaço comunitário. Conforme observado, o aumento da população idosa fomenta a implantação de instituições de longa permanência. Para tanto, compreende-se que ainda existe preconceito com este tipo de instituição para idosos, no entanto busca-se assimilar sua existência a partir das necessidades locais.

Palavras-chave: Instituição de Longa Permanência para Idosos, Relações Comunidade-Instituição, Envelhecimento da População, Assistência Integral à Saúde do Idoso, Participação Comunitária
\end{abstract}

The aim of this study was to evaluate social perceptions on the implementation of a Long Term Care Institutions for Elders in a city of Vale do Taquari/RS, Brazil. It is characterized as a descriptive and exploratory study with a qualitative approach. Data collection was conducted through individual interviews with three people living in the neighborhood to which the Institution for the Aged is in the implementation process. The results showed that the establishment of an institution for the elderly requires a social awareness of their local need. It was found that the quality of care provided to the elderly offers subsidies for families join this new care model. The presentation of the structure to society and conducting multidisciplinary activities are presented as qualifiers principles for acceptance as community space. As noted, the increase in the elderly population fosters the implementation of long-stay institutions. Therefore, it is understood that there is still prejudice against this type of institution for the elderly, however it seeks to assimilate its existence from local needs.

Keywords: Institution for the Aged, Community-Institutional Relations, Ageing Population, Comprehensive Health Care of the Elderly, Community participation

\section{INTRODUÇÃO}

O envelhecimento da população pode ser considerado um fenômeno de abrangência mundial, devido ao elevado crescimento no número de indivíduos que ultrapassam os 60 anos de idade anualmente [1]. Com base nesta informação, há algumas décadas observava-se a inversão da pirâmide etária em países desenvolvidos, principalmente no norte europeu, no entanto a tendência mostra-se visível em países em desenvolvimento, como o Brasil, que possui uma das maiores taxas de idosos da América do Sul [1].

Esta tendência de envelhecimento gradual da população mundial pode estar associada fortemente com a diminuição da fecundidade que, aliada com o aumento da expectativa de vida, os avanços da tecnologia e as intervenções na área da saúde coletiva, contribuíram para a melhoria da qualidade de vida da população [2]. Mesmo assim, o envelhecimento traz consigo 
uma bagagem de características marcadas por fatores típicos como cabelos grisalhos, pele enrugada, perda de peso e redução de massa corpórea, entre outras características fisiológicas que são marcantes nos idosos [3].

Atualmente a trajetória do envelhecimento passa a compor o dia a dia social, flexibilizando os comportamentos afetivos e diminuindo o preconceito com a população idosa, compreendendo-se que a presença de inúmeros estudos que buscam o entendimento das fases do ciclo vital ajuda de certa forma a desmistificar os paradigmas que envolvem o assunto [2]. Tendo em vista esta nova tendência social, ocorre a conscientização da população e, junto a isto, um pensamento crítico e reflexivo capaz de propor ideias para uma adequada intervenção aos problemas que os idosos enfrentam em seu meio social [4].

Sob esse pressuposto e com a crescente preocupação das autoridades, em 1990 foram implementadas a legislação e programas específicos para este segmento populacional decorrentes do entusiasmo da Constituição de 1988 que contém um capítulo de seguridade social que retrata propriamente a temática do envelhecimento social [1]. Diante destas disposições constitucionais, houve o incentivo para a elaboração de legislações complementares sobre o assunto, recebendo destaque a Portaria GM/MS 810 de 1989 e depois a Resolução RDC 283 de 2005, que normatiza o funcionamento das Instituições de Longa Permanência para Idosos (ILPI), definindo a estrutura necessária para abrigar os indivíduos, além dos serviços a serem prestados pela equipe multidisciplinar [4].

Uma ILPI deve fornecer um ambiente com segurança para o idoso institucionalizado que promova o seu bem-estar, fornecendo cuidados especiais, conforme suas necessidades individuais, e suprindo as demandas de adaptação física e logística do espaço de convivência do indivíduo [5]. Nestes locais devem ser fornecidas condições para que o idoso possa receber assistência multiprofissional integral, com controles periódicos e tratamentos adequados, caracterizando-se por prestar uma assistência holística e voltada à seguridade de sua qualidade de vida [1].

Ao longo dos anos, a palavra asilo adquiriu uma significância negativa perante as comunidades, pois frequentemente pode ser referida como uma instituição para idosos carentes, abandonados pelos familiares [3]. O idoso institucionalizado, ou que reside em uma ILPI, evoca uma relação de "pobreza" e "abandono". Essa ideia de abandono adotada pela população em geral, baseada nas palavras asilo, abrigo ou casa de repouso, está bem longe de acabar e nossa realidade demonstra que com o passar dos anos mais idosos estarão residindo nestas instituições [6].

Sendo assim, o principal objetivo deste estudo foi avaliar as percepções sociais diante da implantação de uma Instituição de Longa Permanência para Idosos em um município do Vale do Taquari/RS, Brasil.

\section{MATERIAL E MÉTODOS}

Trata-se de uma pesquisa de campo descritiva e exploratória com abordagem qualitativa. $\mathrm{O}$ estudo foi desenvolvido por meio de entrevista com três indivíduos, dois do sexo masculino e um do sexo feminino, residentes em diferentes bairros em um município do Vale do Taquari/RS, onde uma ILPI está em processo de implantação.

Os sujeitos de pesquisa foram escolhidos aleatoriamente, sendo que os pesquisadores entraram em contato individualmente, propondo sua participação no estudo, explicando os objetivos da pesquisa e os critérios éticos envolvidos, além de agendar um horário disponível para realização da entrevista. Após o aceite de participação, realizou-se uma visita no domicilio dos participantes, onde se aplicou o instrumento de pesquisa que foi elaborado pelos pesquisadores tratando-se de um questionário com perguntas abertas.

Todo o processo de coleta de dados foi realizado mediante a explicação detalhada dos objetivos da pesquisa, as implicações éticas envolvidas, bem como o retorno dos dados à sociedade após a finalização do estudo. Após a explanação dos pesquisadores, os entrevistados puderam sanar quaisquer dúvidas, sendo posteriormente realizada a leitura e assinatura do Termo Consentimento Livre e Esclarecido (TCLE) contendo as informações referentes ao estudo. 
As entrevistas tiveram seus áudios gravados, transcritos, analisados e categorizados conforme preconiza a Análise de Conteúdo de Bardin [7]. Visando preservar a identidade dos entrevistados utilizou-se aleatoriamente nome de flores como codinomes.

O presente estudo integra o projeto de pesquisa "A equipe multiprofissional e o gerenciamento dos investimentos públicos aplicados na saúde dos idosos em um município da região noroeste do estado do Rio Grande do Sul" aprovado pelo Comitê de Ética em Pesquisa (COEP) do Centro Universitário Univates, sob o CAAE ${ }^{\circ} 11992112.8 .0000 .5310$. Foram observados os aspectos éticos conforme Resolução No 466, de 12 de dezembro de 2012 do Conselho Nacional de Saúde (CNS), que determina as diretrizes e normas reguladoras de pesquisas que envolvem seres humanos.

\section{RESULTADOS E DISCUSSÃO}

O conhecimento da população sobre o funcionamento de uma ILPI torna-se essencial em um processo de implantação em determinado espaço, sendo que em alguns casos a própria comunidade baseada em preconceitos desencadeia uma aversão à sua existência. Em meios sociais onde ocorra um preconceito explicito a este tipo de instituição, ações devem anteceder sua implantação baseadas nas premissas de educação em saúde e avaliação epidemiológica do perfil populacional local, correlacionando sua implantação com a real necessidade conforme mostram as falas:

"Já visitei uma casa de Longa Permanência, conhecia como asilo. Vi que os idosos eram bem cuidados, a partir de projetos que ocorriam nas escolas consegui observar como funcionava essa casa. Tinham professores de educação física, eventos sociais em geral isso a uns sete anos atrás." (Cravo)

"É um local de acolhimento em regime integral para o idoso que está em situação de abandono ou negligência por parte da família ou até pelo fato da família não ter um cuidador em casa. Eu penso que se a casa tiver uma boa estrutura, profissionais adequados, com nutricionista, acompanhamento médico, fisioterapeuta, enfermeiros, o idoso fica mais bem amparado nestas casas de longa permanência do que eles estando em casa sofrendo maus tratos. A família às vezes não dá a atenção, se tiver a estrutura necessária e adequada o idoso fica melhor amparado nestas casas." (Cerejeira)

"É uma casa que abrange vários idosos em um lugar só, para que tenham cuidados especializados e de maneira que se sintam em casa. A família que não consegue cuidar do idoso em casa acaba optando pela casa de longa permanência. Sendo um lugar mais proveitoso para o idoso, onde ele possa, além de receber um cuidado especializado, também tem um cronograma de atividades que faz com que eles estejam sempre com alguma atividade programada." (Copo de Leite)

As ILPI recebem idosos com idade normalmente acima de 60 anos, com ou sem apoio familiar, dependentes ou independentes em condição de liberdade, dignidade e cidadania. As casas possuem a finalidade de acolher quaisquer indivíduos que necessitem de seus cuidados, observando-se somente seu caráter, privado ou público [1]. Muitos estudos relacionam a aceitação comunitária das ILPI por mostrar-se como uma das formas de residência para idosos mais viáveis por verificar sua busca em aprimorar as formas de organização assistencial [8].

A decisão em institucionalizar um familiar também se torna outro passo importante na quebra de paradigmas tanto familiares quanto sociais, pois o preconceito e a falta de instruções fomentam discussões acerca da forma com que o idoso será acompanhado durante a permanência na ILPI. 
Várias estratégias instrumentalizam a decisão familiar sobre esta questão, sendo que a própria instituição possui a necessidade de abrir suas portas para a comunidade, permitindo um diálogo direto e saudável sobre suas dúvidas, conforme pode ser visto nas falas:

"Eu colocaria um familiar, mas primeiramente teria que visitar o local, conhecer a forma como trabalha, a decisão de colocá-lo seria pelos melhores cuidados, por ter uma equipe especializada." (Cravo)

"Não colocaria, não tenho nenhum familiar em uma casa de longa permanência, somente em último caso colocaria. Na situação de doença talvez." (Cerejeira)

"Sim, eu colocaria alguém numa casa de Longa Permanência. Acho importante, pois posso não conseguir manter um cuidado como gostaria, então o melhor seria institucional, pois o cuidado que será prestado neste lugar é mais amplo e com mais agilidade em casos de urgência." (Copo de Leite)

Com o crescimento do número de idosos e suas frequentes incapacidades físicas, ocorre um aumento nos gastos financeiros para o cuidado domiciliar bem como a falta de adaptação das estruturas físicas das residências, visto o risco elevado de quedas, e ainda as crescentes taxas de violência contra a pessoa idosa, sendo fatores que levam à institucionalização de um familiar [9]. O trabalho prestado pelas ILPI segue como uma alternativa não familiar para sanar as necessidades básicas de moradia e bem-estar dessa população que necessita de cuidados alternativos e individualizadas [10].

Logo após a segunda guerra mundial, com a ascensão do capitalismo, houve uma série de dificuldades financeiras que modificaram os modelos familiares, sendo necessário que seus membros buscassem sua inserção profissional e isso tem impossibilitado o cuidado de idosos em sua própria residência. Isso ocorreu principalmente com a inclusão da mulher no mercado de trabalho, no entanto a desconfiança quanto ao cuidado oferecido na ILPI torna-se um dos pontos que favorece o preconceito social pelas instituições, conforme as falas:

"Em muitos casos as famílias não acreditam que o cuidado é pertinente às necessidades que o idoso necessita, em várias rotinas do dia a dia. Eles têm tudo o que precisam nestas casas, café da manhã, lanche da manhã, almoço, lanche da tarde, janta, possuem cuidados 24 horas." (Cravo)

"Os cuidados ao idoso devem ser prestados por profissionais, que façam ele se sentir acolhido, querido, dar a atenção que ele necessita os cuidados necessários. Acredito que num ambiente legal $e$ aconchegante onde a idosa ira se sentir bem e vai viver melhor. $O$ idoso deve receber carinho e atenção de toda equipe para que ele se sinta como se estivesse em casa, passando segurança também aos familiares que muitas vezes possuem dúvidas quanto à qualidade da assistência oferecida." (Cerejeira)

"O cuidado em uma casa de longa permanência deve ser bem estruturado, pois são pessoas que já viveram bastante tempo, e necessitam de um cuidado especial tanto para o banho como comer, deitar na cama e escovar os dentes, em alguns casos. Deve haver profissionais capacitados, e que gostem dessa área, e acima de tudo que mantenham um diálogo aberto com os familiares sanando as dúvidas que aparecerem." (Copo de Leite) 
As ILPI se caracterizam por seu sistema social organizacional buscando desenvolver atividades que viabilizam o cumprimento e capacitação de metas específicas e das necessidades humanas [9]. Ao averiguar as condições específicas desses idosos, cabe à instituição proporcionar uma assistência voltada para as necessidades pertinentes de seus residentes, sendo importante a presença de familiares neste contexto, possuindo o contato direto com a equipe de apoio a saúde [1].

Neste sentido, as ILPI dispõem de uma estrutura baseada em normas regulamentadoras que asseguram uma assistência efetiva e comprometida com os idosos institucionalizados, servindo como apoio à família que não possui condições adequadas para acolher seu familiar. Para tanto, a estrutura das ILPI fomentam a discussão sobre a qualidade dos serviços prestados, sendo um dos itens mais avaliados pela sociedade, quando se pretende institucionalizar um idoso, conforme as falas:

\begin{abstract}
"Com certeza se existe uma boa estrutura, adequada para o idoso. Muitos não conseguem caminhar direito, necessitam de um corrimão, para aqueles que não conseguem caminhar uma cadeira de rodas, e o espaço da casa todo adaptado para este idoso. O fato dele estar doente, ter o equipamento, material e a equipe para prestar o atendimento correto, sendo assim mantendo ele em boas condições e saudável." (Cravo)
\end{abstract}

"Acho que sim, a estrutura física da instituição deve ser adequada ao idoso, pois ele requer mais cuidado e mais atenção." (Cerejeira)

"Pode influenciar sim, dependendo da visão que eu tiver da estrutura do local, da organização, limpeza, rotina e equipe de profissionais. Quanto mais vantagens ela trazer para meu familiar mais convencido estarei, que é um local onde será bem cuidado." (Copo de Leite)

Uma ILPI deve fornecer um ambiente de segurança que promova o acolhimento do idoso fornecendo os cuidados especiais dos quais ele necessita, contribuindo para sua qualidade de vida e satisfação de ambos [9]. Perante a sociedade, a estrutura física de uma instituição torna-se o espelho de todo o serviço oferecido, sendo que a avaliação empírica realizada pelos sujeitos busca características que lembrem sua própria residência e não uma instituição hospitalar, conferindo ao mesmo tempo a assistência e a privacidade de seus familiares [11].

No contexto assistencial, a presença de uma equipe multiprofissional assegura à sociedade que o idoso estará sendo cuidado, acredita-se que uma assistência efetiva não depende de quantos profissionais atuam em uma instituição e sim da qualidade de sua organização e nível de conhecimento na área. Mesmo assim, a atuação de vários profissionais concretiza a necessidade de criação de um cuidado humanizado e moldado em princípios da interdisciplinaridade, conforme as falas:

"Hoje para abrir uma casa de longa permanência deve seguir leis, que
regulamentam a contratação de funcionários de grau superior como
nutricionista, enfermeiro, um administrador, por isso hoje em dia a
casa tem uma visão diferente, pelos cuidados que são prestados aos
idosos. Esse cuidado prestado por uma equipe com vários profissionais
tem sim uma visão mais ampla do idoso, buscando sanar suas
dificuldades na integra." (Cravo)
"Acho que sim, como já havia mencionado nas outras perguntas, se o
local for formado por uma equipe de profissionais qualificados, que
estejam prontos e capacitados para prestar a assistência que ele
necessita, acredito que a casa seja muito viável, o idoso vai se sentir
bem, a grande maioria dos idosos precisa de atenção, caminhar, 
conversar, jogar uma carta, querem carinho, uma casa bem estruturada para o idoso, onde ficará bem acolhido tendo carinho e atenção é o que importante." (Cerejeira)

"Com certeza essa casa de Longa Permanência deve ter profissionais que possam prestar um cuidado mais amplo para este idoso. A equipe deve ter médicos, enfermeiros, técnicos de enfermagem, nutricionista, psicóloga, cuidadores e cozinheiras. A equipe multiprofissional tem um olhar do idoso além de um ponto de vista e sim de vários!". (Copo de Leite)

As ILPI devem oferecer uma equipe assistencial, conforme os preceitos legais, que garantam cuidados aos residentes, conforme grau de dependência, assegurando o acesso a uma infinidade de medidas terapêuticas de apoio, tanto diretamente ao indivíduo, como à própria estrutura [12]. Portanto, faz-se necessário que as instituições possuam uma equipe multiprofissional capacitada na área de gerontologia para proporcionar um cuidado diferenciado ao idoso, prestando auxilio em suas ações e desenvolvendo um papel fundamental na gestão organizacional do serviço [13].

\section{CONCLUSÃO}

Através deste estudo obtivemos o desfecho da percepção de alguns moradores da comunidade sobre a implantação de uma ILPI, podendo-se observar a visão dos entrevistados e oportunizar a vivência de um processo de implantação institucional. Através dos relatos obtidos, podemos concluir que a visão de que a ILPI seria um depósito de idosos, um lugar de abandono, está sendo desconstruída. Pode-se vislumbrar que a sociedade mostra-se aberta para reconstruir seus conceitos e desconstruir antigos tabus.

Conforme observado no decorrer do estudo à população idosa encontra-se em uma perspectiva de crescimento contínuo, para tanto, devemos enquanto sociedade estar preparados para prestar o apoio necessário a esta população, de maneira digna, estabelecendo uma relação de confiança e priorizando um cuidado integral. Esse estudo reflete o movimento de institucionalização do idoso como a melhor opção para casos onde a família não possui condições de suprir suas necessidades, principalmente em casos de patologias degenerativas.

As ILPI vêm estabelecendo seu lugar nas comunidades, de maneira que buscam na realidade da população a viabilidade dos serviços oferecidos, bem como a presença de seu público alvo, dispondo de uma estrutura capaz de atender à demanda emergente. Percebeu-se que é de suma importância a presença da equipe multiprofissional no atendimento ao idoso institucionalizado aplicando seus conhecimentos e tendo uma visão mais ampla deste residente.

Este estudo contribui para os processos de implantação de ILPI, sendo capaz de demonstrar as percepções da população quanto às novas demandas assistenciais para a população idosa, viabilizando um cuidado holístico e digno.

\section{REFERÊNCIAS BIBLIOGRÁFICAS}

1. Netto MP. Gerontologia: a velhice e o envelhecimento em visão globalizada. São Paulo: Atheneu; 2002. $524 \mathrm{p}$.

2. Brito AA. Atividade econômica da população com 60 anos ou mais no Rio Grande do Sul e o impacto sobre a composição das rendas domiciliares. Santa Cruz do Sul: UNISC, 2007.

3. Brue LJ, Carroll M. Enfermagem para idosos. São Paulo: Andrei; 1991.

4. Cortelletti IA e cols. Idosos Asilados: um estudo Gerontológico. Caxias do Sul, RS: Educs/Edipucrs; 2004. $133 \mathrm{p}$.

5. Cortelletti IA, Casara MB, Heredia VB. Idoso Asilado: um estudo Gerontológico. Caxias do Sul, RS; 2010. 134 p.

6. Nicola P. Geriatria. A velhice e o envelhecimento em visão globalizada. São Paulo; Atheneu; 1986.

7. Bardin L. Análise de conteúdo. 70ed. Lisboa/Portugal, LDA; 2011.

8. Siqueira RL, Botelho MIV, Coelho FMG. A velhice; algumas considerações teóricas e conceituais. Ciênc Saúde Coletiva 2002;7(4):899-906. 
9. Marinho LM, Vieira MA, Costa SDM, Andrade JMO. Grau de dependência de idosos residentes em Instituições de Longa Permanência. Rev Gaúcha Enferm 2013;34(1):104-110. doi: 10.1590/S198314472013000100013

10. Creutzberg M, Gonçalves LHT, Sobottka EA, Ojeda B. A Instituição de Longa Permanência para Idosos e o sistema de saúde. Rev Latino-Am Enferm 2007;15(6):1144-1149. doi:10.1590/S010411692007000600014

11. Costa MCNS, Mercadante EF. O idoso residente em ILPI (Instituição de Longa Permanência do Idoso) e o que isso representa para o sujeito idoso. Rev Kairos Gerontol 2013;16(2):209-222.

12. Salcher EBG, Portella MR, Scortegagna HDM. Cenários de Instituições de Longa Permanência para Idosos: retratos da realidade vivenciada por equipe multiprofissional. Rev Bras Geriatr Gerontol 2015;18(2):259-272. doi: 10.1590/1809-9823.2015.14073

13. Alves-Silva JD, Comin FS, Santos MAD. Idosos em Instituições de Longa Permanência: Desenvolvimento, Condições de vida e Saúde. Psicol Reflex Crit 2012;26(4):820-830. doi: 10.1590/S0102-79722013000400023 